\title{
Rehabilitation programs monitored by functional independence measure: an observational study
}

\begin{abstract}
The Functional Independence Measure (FIM) is used in the Rehabilitation Centre of the Buerger Hospital Solothurn as a part of the sustainable quality development and maintenance. While FIM in the rehabilitation of stroke patients is well documented, its use in other rehabilitation patients is less common. The purpose of this study is to describe the FIM scores on admission and discharge of all patients discharged 1998 and to assess achieved improvements. The FIM was completed on admission and discharge by a nurse for every patient treated at the Rehabilitation Centre during 1998( $\mathrm{N}=250)$. The t-test for paired samples showed that the patients improved significantly $(p<0.005)$ in all measured dimensions. These results indicate the usefulness of FIM in monitoring a large sample in this setting. The FIM provides differentiated measures of various treatment dimensions for all studied groups of patients. The results also indicate efficacy of rehabilitative treatment. Rehabilitation care as monitored by Functional Independence Measure
\end{abstract}

\author{
Volume 2 Issue I - 2017
}

Ladislav K Valach,' Selz Beat ${ }^{2}$

Rehabilitation Centre, Buerger Hospital Solothurn, Switzerland

Correspondence: Ladislav K Valach, Rehabilitation Centre, Buerger Hospital Solothurn, Switzerland,Tel ++4I792 I62 I92, Email ladislav.valach@hispeed.ch

Received: June 18, 2017 | Published: November 03, 2017

\section{Introduction}

Functional independence is a relevant goal of treatment for patients in rehabilitation. The philosophy of evidence based medicine and nursing facilitates development of recognized standards in assessment in health care. ${ }^{1,2}$ However, there still is a discussion regarding assumptions for assessing functional independence. ${ }^{3}$ The Functional Independence Measure (FIM) is one of the most widely used, valid and reliable instruments for collecting observational data on the patients' degree of self reliance in various areas of everyday life. ${ }^{4,5}$ The Functional Independence Measure (FIM) was introduced several years ago at the Rehabilitation Centre of the Medical Clinic, Buerger Hospital Solothurn, Switzerland, to assess the outcome of the rehabilitation. In measuring patients' functional independence on admission and discharge we were able to monitor any significant changes and improvements in different areas of everyday life and in various diagnostic groups of patients.

\section{Methods}

FIM is an 18 item observational sheet and interview schedule. It is a reliable and valid instrument for collecting data on the patients' degree of functional independence in various areas of everyday life. Each of the patient's activities (eating, grooming, bladder management, social interaction etc.) is rated between 1(totally dependent) and 7(fully independent). The FIM was completed by nurses for each and every patient without exception treated at the Rehabilitation Centre during 1998( $\mathrm{N}=250)$. Additional personal and socio demographic data were also collected. The observations were made on admission and discharge of the patients. They were collected as a part of the rehabilitation procedure and not a within an additional research project, as they are included in the clinical data. The Rehabilitation Centre provides stationary ( 24 bed unit) and semi stationary treatment (4 beds). It is adjoined to an acute hospital. The 250 patients were either post surgery ( $\mathrm{N}=58,23.2 \%)$, or suffered vascular brain damage $(\mathrm{N}=72,28.8 \%)$, traumatic brain damage $(\mathrm{N}=6,2.4 \%)$, rheumatologic illness $(\mathrm{N}=44,17.6 \%)$, geriatric multi organ illness $(\mathrm{N}=21,8.4 \%)$ or other neurological illnesses $(\mathrm{N}=49,19.2 \%)$. There were $49.3 \%$ women, $50.7 \%$ men, mean age 65.3 ( $\mathrm{sd}=16.5)$.

\section{Results}

The t-test for paired samples showed that the patients improved significantly $(p<0.005)$ in all measured dimensions, reaching the largest effect size in walking or in moving around in a wheel chair (.45), then in walking on the stairs, in transfer from bed to chair, transfer to the toilet and in bathing. The patients reached the highest values in independent eating and drinking, bowel management and social interaction. The lowest values were in walking on the stairs and in lower body dressing (Table 1). The highest effect size was reached in locomotion (.44), transfer (.39), self care (.35), sphincter control (.26), communication (.21) and the lowest in social cognition (.12).

Table I All patients $(\mathrm{N}=250)$ (t-test for paired samples)

\begin{tabular}{lllllllll}
\hline & & \multicolumn{2}{l}{ Admission } & \multicolumn{2}{c}{ Discharge } & \multicolumn{2}{c}{ T Effect size } \\
\cline { 3 - 6 } & & Mean & Std dev & Mean & Std dev & & \\
\hline & Self care: & 27.63 & 10.43 & 31.33 & 9.78 & $-9.07 * *$ & 0.35 \\
A & Eating & 5.7 & 0.45 & 6.1 & 1.22 & $-5.39 * *$ & 0.28 \\
B & Grooming & 5.1 & 1.62 & 5.6 & 1.49 & $-7.15 * *$ & 0.31 \\
C & Bathing & 4 & 1.97 & 4.7 & 1.86 & $-8.29 * *$ & 0.36 \\
D & Upper body dressing & 5 & 1.8 & 5.6 & 1.63 & $-7.62 * *$ & 0.33 \\
\hline
\end{tabular}


Table Continued....

\begin{tabular}{|c|c|c|c|c|c|c|c|}
\hline & & \multicolumn{2}{|c|}{ Admission } & \multicolumn{2}{|c|}{ Discharge } & \multirow[t]{2}{*}{$\mathbf{T}$} & \multirow[t]{2}{*}{ Effect size } \\
\hline & & Mean & Std dev & Mean & Std dev & & \\
\hline \multirow[t]{2}{*}{$\mathrm{F}$} & Toiletting & 4.1 & 2.48 & 4.9 & 2.31 & $-7.68^{* *}$ & 0.32 \\
\hline & Sphincter control: & 10.32 & 3.78 & 11.82 & 3.19 & $-6.32^{* *}$ & 0.26 \\
\hline G & Blader management & 5.2 & 2.24 & 5.7 & 1.9 & $-6.00 * *$ & 0.22 \\
\hline \multirow[t]{2}{*}{$\mathrm{H}$} & Bowel management & 5.7 & 1.71 & 6.1 & 1.43 & $-5.64 * *$ & 0.33 \\
\hline & Transfer: & 13.58 & 6.01 & 15.92 & 5.14 & $-9.48^{* *}$ & 0.39 \\
\hline I & Bed/chair/WC & 4.7 & 1.99 & 5.5 & 1.68 & $-9.53^{* *}$ & 0.4 \\
\hline J & Toilet & 4.7 & 2.04 & 5.5 & 1.96 & $-8.92^{* *}$ & 0.39 \\
\hline \multirow[t]{2}{*}{ K } & Tub/shower & 4.2 & 2.12 & 4.9 & 3.61 & $-8.15^{* *}$ & 0.33 \\
\hline & Locomotion: & 7.79 & 4 & 9.56 & 1.69 & $-10.50 * *$ & 0.44 \\
\hline$L$ & Walk/WC & 4.5 & 2 & 5.4 & 1.69 & $-9.38 * *$ & 0.45 \\
\hline \multirow[t]{2}{*}{ M } & Stairs & 3.3 & 2.27 & 4.2 & 2.21 & $-9.55 * *$ & 0.4 \\
\hline & Communication: & 10.57 & 3.4 & 11.28 & 2.88 & $-5.84 * *$ & 0.21 \\
\hline $\mathrm{N}$ & Comprehension & 5.4 & 1.67 & 5.7 & 1.4 & $-5.88 * *$ & 0.18 \\
\hline \multirow[t]{2}{*}{ O } & Expression & 5.2 & 1.84 & 5.6 & 1.6 & $-5.20 * *$ & 0.22 \\
\hline & Social cognition: & 15.86 & 4.87 & 16.44 & 4.32 & $-3.7 \mid * *$ & 0.12 \\
\hline$P$ & Social interaction & 5.8 & 1.5 & 6 & 1.28 & $-3.15^{*}$ & 0.13 \\
\hline Q & Problem solving & 4.8 & 1.9 & 5 & 1.75 & $-2.86 *$ & 0.11 \\
\hline $\mathrm{R}$ & Memory & 5.3 & 1.83 & 5.5 & 1.66 & $3.58^{* *}$ & 0.11 \\
\hline
\end{tabular}

** $\mathrm{p}<0.001$

$* p<0.005$

The analysis indicated some differences in gain of functional independence among patients with different diagnoses. Although it has been reported that adding ICD-9-CM codes does not greatly improve the prediction of the length of stay of the patients ${ }^{6}$ the various degree of independence in different diagnostic groups must be considered. The patients with vascular brain damage $(n=72)$ improved their independence in all areas of everyday life in a highly significant manner $(\mathrm{p}<0.005)$ (Table 2$)$. They reached the highest effect size values in locomotion (.43) and in self-care (.39). The post surgery patients $(\mathrm{N}=58)$ also improved in all dimensions except in communication. However, their rating of communication on admission was higher than the rating of communication of the vascular brain damage patients on discharge (Table 3). Their highest effect size was in locomotion (.72) and in transfer (.66). This group of patients improved most of all patients. Patients with rheumatologic illness $(\mathrm{N}=44)$ improved their functional independence in self-care, sphincter control, transfer, locomotion, communication, but not in social cognition (Table 4). They also reached the highest effect size in locomotion (.32) and in transfer (.29). Finally, the patients with geriatric multi organ illness $(\mathrm{N}=21)$ improved significantly in the motor items but not in the cognitive items (Table 5). Their highest effect sizes were .54 for locomotion and .43 for transfer.

Table 2 Patients with vascular brain damage ( $N=72)$ ( $t$-test for paired samples).

\begin{tabular}{|c|c|c|c|c|c|c|}
\hline & \multicolumn{2}{|c|}{ Admission } & \multicolumn{2}{|c|}{ Discharge } & \multirow[t]{2}{*}{$\mathbf{T}$} & \multirow[t]{2}{*}{ Effect size } \\
\hline & Mean & Std dev & Mean & Std dev & & \\
\hline Self care(6 items): & 25.69 & 10.7 & 29.81 & 10.07 & & 39 \\
\hline Sphincter control(2 items): & 10.08 & 4.38 & 11.49 & 3.82 & & 32 \\
\hline Transfer(3 items): & 12.78 & 6.21 & 15.08 & 5.56 & $-4.95 * *$ & 37 \\
\hline Locomotion(2 items): & 7.43 & 3.98 & 9.14 & 3.97 & $-5.52 * *$ & 43 \\
\hline Communication(2 items): & 9.36 & 3.53 & 10.51 & 2.64 & $-5.20 * *$ & 33 \\
\hline Social cognition(3 items): & 14.49 & 4.97 & 15.39 & 4.02 & $3.44^{* *}$ & 18 \\
\hline
\end{tabular}

** $p<0.001$ 
Table 3 Post surgery patients $(\mathrm{N}=58)$ (t-test for paired samples)

\begin{tabular}{|c|c|c|c|c|c|c|}
\hline & \multicolumn{2}{|c|}{ Admission } & \multicolumn{2}{|c|}{ Discharge } & \multirow[t]{2}{*}{$\mathbf{T}$} & \multirow[t]{2}{*}{ Effect size } \\
\hline & Mean & Stddev & Mean & Stddev & & \\
\hline Self care: & 25.53 & 9.36 & 30.95 & 8.96 & $-5.69 * *$ & 0.58 \\
\hline Sphincter control & 10.76 & 3.25 & 11.85 & 3.08 & $-3.03^{*}$ & 0.34 \\
\hline Transfer: & 11.62 & 5.87 & 15.47 & 4.71 & $-7.07 * *$ & 0.66 \\
\hline Locomotion: & 6.47 & 3.8 & 9.22 & 3.17 & $-6.94 * *$ & 0.72 \\
\hline Communication: & 11.35 & 3.06 & 11.67 & 3.12 & -1.38 & 0.1 \\
\hline Social cognition & 16.09 & 4.27 & 16.98 & 4.49 & $-2.52+$ & 0.21 \\
\hline
\end{tabular}

$* * \mathrm{p}<0.001$

$* p<0.005$

$+\mathrm{p}<0.05$

Table 4 Patients with rheumatologic illness $(\mathrm{N}=44)$ ( $\mathrm{t}$-test for paired samples)

\begin{tabular}{|c|c|c|c|c|c|c|}
\hline & \multicolumn{2}{|c|}{ Admission } & \multicolumn{2}{|c|}{ Discharge } & \multirow[t]{2}{*}{$\mathbf{T}$} & \multirow[t]{2}{*}{ Effect size } \\
\hline & Mean & Std dev & Mean & Std dev & & \\
\hline Self care: & 37.14 & 5.92 & 38.73 & 5.22 & $-2.85+$ & 0.27 \\
\hline Sphincter control & 13.25 & 1.56 & 13.57 & I & $-2.26+$ & 0.21 \\
\hline Transfer: & 18.25 & 3.71 & 19.34 & 2.98 & $-3.13^{*}$ & 0.29 \\
\hline Locomotion: & 11.18 & 2.87 & 12.09 & 2.65 & $-3.85^{* *}$ & 0.32 \\
\hline Communication: & 12.23 & 2.24 & 12.68 & 1.81 & $-2.89+$ & 0.2 \\
\hline Social cognition & 19.05 & 2.85 & 18.91 & 2.73 & 0.76 & -0.05 \\
\hline
\end{tabular}

$* * \mathrm{p}<0.001$

$* p<0.005$

$+p<0.05$

Table 5 Patients with geriatric multi organ illness ( $N=2 \mathrm{I})$ (t-test for paired samples)

\begin{tabular}{|c|c|c|c|c|c|c|}
\hline & \multicolumn{2}{|c|}{ Admission } & \multicolumn{2}{|c|}{ Discharge } & \multirow[t]{2}{*}{$\mathbf{T}$} & \multirow[t]{2}{*}{ Effect size } \\
\hline & Mean & Std dev & Mean & Std dev & & \\
\hline Self care: & 26.1 & 9.68 & 29.1 & 8.59 & $-2.83+$ & 0.31 \\
\hline Sphincter control & 10.52 & 3.86 & 11.48 & 3.19 & $-2.12+$ & 0.25 \\
\hline Transfer: & 13.57 & 5.14 & 15.76 & 4.02 & $-3.28+$ & 0.43 \\
\hline Locomotion: & 6.67 & 3.98 & 8.81 & 3.2 & $-4.78^{* *}$ & 0.54 \\
\hline Communication: & 10.05 & 3.54 & 10.43 & 3.25 & -1.63 & 0.11 \\
\hline Social cognition & 15.76 & 4.53 & 16.29 & 3.94 & 1.71 & 0.12 \\
\hline
\end{tabular}

$* * \mathrm{p}<0.001$

$+p<0.05$

\section{Discussion}

Using Functional Independence Measure in stroke patients and, generally, in patients with vascular brain damage is an established outcome measurement procedure. There are reports on the values these patients reach ${ }^{7}$ on their FIM gain and on the structure of these measures. ${ }^{8}$ The admission FIM in patients after stroke $(>70)$, together with several other variables, such as age $(<60)$, being married 
and living at home prior stroke predicts whether the patients are discharged home. ${ }^{9}$ Others indicate that a discharge FIM score of 80 or above had a high specificity and sensitivity with patients' ${ }^{6}$ discharge to their home. ${ }^{10}$ Mokler et al. ${ }^{11}$ found that three admission FIM variables (bladder management, toilet transfers, memory) and three discharge FIM variables (upper body dressing, bed/chair tranfers, comprehension) were associated with discharge destination with up to $75 \%$ accuracy. The admission FIM total has been reported as best predicting discharge FIM self care thus suggesting that dependency in physical activities of daily living after stroke is primarily determined by degree of motor impairment. ${ }^{12}$

Goldsmith et al. ${ }^{13}$ report that FIM motor function scores at admission (along with age and geographic region) best predicted rehabilitation length of stay in patients after stroke. Gupta et al. ${ }^{14}$ reported that all the parameters improved significantly at the time of discharge as measured by FIM for acquired brain injury patients. It has also been indicated ${ }^{15}$ that FIM helps in predicting retourn to work in acquired brain injury patients. The FIM score at rehabilitation admission was significantly associated with return to driving in traumatic brain injured patients. ${ }^{16}$ Feder et al. ${ }^{17}$ Maintain that there is no difference in average total FIM scores when patients are divided by side of damage by stroke (left or right hemisphere). It also is suggested that patients after stroke without substantial impairment reduction show disability decline during rehabilitation. Thus, as rehabilitation has an independent role in improving function beyond that explained by neurologic recovery, the FIM as a measures of disability is an important indicator of rehabilitation progress. ${ }^{18}$ FIM can also be used to create benchmarks in order to guide development and quality improvement and in establishing patients goals in stroke rehabilitation. ${ }^{19}$ Additionally, it has been indicated that lower FIM scores correlate with higher depression scores. ${ }^{20}$

There also are some critical voices indicating that a specific rehabilitation is not well represented by FIM such as the improvement of the upper limb function after stroke. ${ }^{21}$ It has been suggested that the International Classification of Functioning, Disability and Health (ICF) is probably more comprehensive than FIM in describing both capacity and performance in stroke patients. ${ }^{22}$ FIM seems to be only of limited value in assessing functional change on a follow-up. Discharge and follow-up total FIM ${ }^{\mathrm{TM}}$ scores are highly correlated indicating that collection of the follow-up FIM may not provide additional information after a patient has been discharged from inpatient rehabilitation. ${ }^{23}$

Our study with Swiss patients, using a German version of the FIM informs us about the FIM values we obtained with patients with vascular brain damage. The effect sizes indicate that our patients improve mostly in locomotion, self-care and in transfer and also show substantial improvement in communication and in sphincter control. In contrast to FIM studies with patients after stroke there are fewer studies with rehabilitation patients after surgery. The predictive value of the FIM was not consistent in patients with amputation. ${ }^{24}$ However, the predictability of rehabilitation success was high in patients with high FIM at admission. It has been indicated that discharge FIM score for traumatic amputees is well predicted by medical comorbidity and for vascular amputees by stump comorbidity (an inverse relationship in both). ${ }^{25}$

Rush et al. ${ }^{26}$ pointed out that the admission FIM score does not predict successful prosthetic rehabilitation in lower extremity amputee patients as it does not correlate with the Houghton Scale for prosthetic use. Morrison et al. ${ }^{27}$ maintain that FIM may not be useful in detecting changes in follow up measure for early lower limb amputees but that it is suitable for measuring changes during the inpatient stage of rehabilitation. FIM as an outcome measure in post surgery patients proved to be an excellent indicator of rehabilitation progress in our sample as the FIM on discharge vs. FIM on admission show the highest effect size from all diagnosis groups.

Using FIM as an outcome measure in geriatric rehabilitation has been reported in a number of studies. As the geriatric multi organ illness patients tend to be older than other rehabilitation patients it is important to know whether FIM is also a valid and reliable measure in older patients. Pollak et al. ${ }^{28}$ studied forty nine residents and found that FIM is useful as a functional assessment instrument for people who are 80 or more years old. The motor activity and its independence from the cognitive functions in the geriatric group of patients attracted some interest Ruchinskas et al. ${ }^{29}$ maintain that although cognitive measures predict total FIM scores on admission and discharge, they do not predict FIM ambulation score. In our study we found no significant improvement in cognitive functions as represented by FIM in geriatric multi organ illness patients but a significant improvement in FIM motor score. However, it has been reported that geriatric patients with higher FIM social cognitive items are more often discharged home. ${ }^{30}$ Diamond et al. ${ }^{31}$ indicate that geriatric patients with cognitive dysfunction should be considered for rehabilitation if functional gains will affect their quality of life. It is also important to note that patients of geriatric rehabilitation units classified as depressed at discharge have lower FIM scores at admission and at discharge. ${ }^{32}$ FIM scores, including FIM gain of elderly patients were significantly lower than those of middle-aged patients. ${ }^{33}$ It has been proposed, ${ }^{34}$ that in patients with a dementia diagnosis the FIM-gains and thus the rehabilitation success, should be measured by the motor subscale of the FIM, rather than the total FIM score, or the gain relative to the maximal FIM score.

Although outcome measures are used in rehabilitation of patients with rheumatologic and musculoskeletal illnesses the functional independence as operationalized in and monitored by FIM is not often addressed. Although FIM has been reported as one of the mostly used standardized outcome measure in rehabilitation settings in $\mathrm{UK}^{35}$ there are other instruments such as SF-36, HAQ (Health Assessment Questionnaire $^{36}$ or WOMAC. Our study shows that some improvement in the patients with rheumatologic illness could be represented by FIM. We found significant improvement in all subscales but in social cognition and effect sizes between 0.20 and 0.32 . In methodical terms, this clinical study differs from a study which employes blind rating and a control group for treatment and care intervention. However, there are some data indicating that, as far as outcomes are concerned, the results of this assessment may be identical with the results provided by such a methodically rigorous study. ${ }^{37,38}$ Consequently, it can be maintained that the patients in all diagnoses groups are significantly better off in their functional independence on discharge than they were on admission.

\section{Acknowledgements}

The authors are in debt to all patients and nurses of the Rehabilitation Centre, Buerger Hospital Solothurn, Switzerland, for their participation in this study.

\section{Conflict of interest}

The author declares no conflict of interest. 


\section{References}

1. Deaton C. Outcome measurement and evidence-based nursing practice. $J$ Cardiovasc Nurs. 2001;15(2):83-86.

2. Kitson A. Towards evidence-based quality improvement: perspectives from nursing practice. International Journal of Quality in Health Care. 2000;12(6):459-464.

3. McKenna H, Cutcliffe J, McKenna P. Evidence-based practice: demolishing some myths. Nurs Stand. 2000;14(16):39-42.

4. Granger CV, Hamilton BB, Linacre JM, et al. Performance profiles of the functional independence measure. Am J Phys Med Rehabil. 1993;72(2):84-89.

5. Grimby G, Gudjonsson G, Rodhe M, et al. The functional independence measure in Sweden: experience for outcome measurement in rehabilitation medicine. Scandinavian Journal of Rehabilitation Medicine. 1996;28(2):51-62.

6. Stineman MG, Escarce JJ, Tassoni CJ, et al. Diagnostic coding and medical rehabilitation length of stay: their relationship. Arch Phys Med Rehabil. 1998;79(3):241-248.

7. Gresham GE, Granger CV, Linn RT, et al. Status of fuctional outcomes for stroke survivors. Phys Med Rehabil Clin N Am. 1999;10(4):957-966.

8. Cavanagh SJ, Hogan K, Gordon V, et al. Stroke-specific FIM models in an urban population. J Neurosci Nurs. 2000;32(1):17-21.

9. Ween JE, Mernoff ST, Alexander MP. Recovery rates after stroke and their impact on outcome prediction. Neurorehabil Neural Repair. 2000;14(3):229-235.

10. Black TM, Soltis T, Bartlett C. Using the functional independence measure instrument to predict stroke rehabilitation outcomes. Rehabil Nurs. 1999;24(3):109-114.

11. Mokler PJ, Sandstrom R, Griffin M, et al. Predicting discharge destination for patients with severe motor stroke: important functional tasks. Neurorehabil Neural Repair. 2000;14(3):18-185.

12. Chae J, Johnston M, Kim H, et al. Admission motor impairment as a predictor of physical disability after stroke rehabilitation. Am J Phys Med Rehabil. 1995;74(3):218-223.

13. Grant $\mathrm{C}$, Goldsmith $\mathrm{CH}$, Anton HA. Inpatient stroke rehabilitation lengths of stay in Canada derived from the National Rehabilitation Reporting System, 2008 and 2009. Arch Phys Med Rehabil. 2014;95(1):74-78.

14. Patil M, Gupta A, Khanna M, et al. cognitive and functional outcomes following inpatient rehabilitation in patients with acquired brain injury: A Prospective Follow-up Study. J Neurosci Rural Pract. 2017;8(3):357363.

15. Franceschini M, Massimiani MP, Paravati S, et al. Return to work: A Cut-Off of FIM gain with montebello rehabilitation factor Score in Order to identify predictive factors in subjects with acquired brain injury. PLoS One. 2016;11(10): 0165165.

16. Cullen N, Krakowski A, Taggart C. Functional independence measure at rehabilitation admission as a predictor of return to driving after traumatic brain injury. Brain Inj. 2014;28(2):189-195.

17. Ring H, Feder M, Schwartz J, et al. Functional measures of first-stroke rehabilitation inpatients: usefulness of the Functional Independence Measure total score with clinical rationale. Arch Phys Med Rehabil. 1997;78(6):630-635.

18. Roth EJ, Heinemann AW, Lovell LL, et al. Impairment and disability: their relation during stroke rehabilitation. Arch Phys Med Rehabil. 1998;79(3):329-335.
19. Stineman MG, Fiedler RC, Granger CV, et al. Functional task benchmarks for stroke rehabilitation. Arch Phys Med Rehabil. 1998;79(5):497-504.

20. Singh A, Black SE, Herrmann N, et al. Functional and neuroanatomic correlations in poststroke depression: the Sunnybrook Stroke Study. Stroke. 2000;31(3):637-644.

21. Williams BK, Galea MP, Winter AT. What is the functional outcome for the upper limb after stroke? Aust J Physiother. 2001;47(1):19-27.

22. Tarvonen SS, Laimi K, Kauko T, et al. Concepts of capacity and performance in assessment of functioning amongst stroke survivors: A comparison of the functional independence measure and the international classification of functioning, disability and health. $J$ Rehabil Med. 2015;47(7):662-664.

23. Passalent LA, Tyas JE, Jaglal SB, et al. The FIM ${ }^{\mathrm{TM}}$ as a measure of change in function after discharge from inpatient rehabilitation: a Canadian perspective. Disabil Rehabil. 2011;33(7):579-588.

24. Muecke L, Shekar S, Dwyer D, et al. Functional screening of lower-limb amputees: a role in predicting rehabilitation outcome? Arch Phys Med Rehabil. 1992;73(9):851-858.

25. Melchiorre PJ, Findley T, Boda W. Functional outcome and comorbidity index in the rehabilitation of the traumatic versus the cardiovascual unilateral lower limb amputee. Am J Phys Med Rehabil. 1996;75(1):914.

26. Leung EC, Rush PJ, Devlin M. Predicting prosthetic rehabilitation outcome in lower limb amputee patients with the functional independence measure. Arch Phys Med Rehabil. 1996;77(6):605-608.

27. Panesar BS, Morrison P, Hunter J. A comparison of three measures of progress in early lower limb amputee rehabilitation. Clinical Rehabilitation. 2001;15(2):157-171.

28. Pollak N, Rheault W, Stoecker JL. Reliability and validity of the FIM for persons aged 80 years and above from a multilevel continuing care retirement community. Arch Phys Med Rehabil. 1996;77(10):1056-1061.

29. Ruchinskas RA, Singer HK, Repetz NK. Cognitive status and ambulation in geriatric rehabilitation: walking without thinking? Arch Phys Med Rehabil. 2000;81(9):1224-1228.

30. MacNeill SE, Lichtenberg PA. Home alone: the role of cognition in return to independent living. Arch Phys Med Rehabil. 1997;78(7):755-758.

31. Diamond PT, Felsenthal G, Macciocchi SN, et al. Effect of cognitive impairment on rehabilitation outcome. Am J Phys Med Rehabil. 1996;75(1):40-43.

32. Diamond PT, Holroyd S, Macciocchi SN, et al. Prevalence of depression and outcome on the geriatric rehabilitation unit. Am J Phys Med Rehabil. 1995;74(3):214-217.

33. Naruishi K, Kunita A, Kubo K, et al. Predictors of improved functional outcome in elderly inpatients after rehabilitation: a retrospective study. Clin Interv Aging. 2014;5(9):2133-2141.

34. Muir HSW, Fat GL, Mackenzie R, et al. Defining rehabilitation success in older adults with dementia--results from an inpatient geriatric rehabilitation unit. J Nutr Health Aging. 2016;20(4):439-445.

35. Turner SL, Turner ST. The use of standardized outcome measures in rehabilitation centres in the UK. Clinical Rehabilitation. 1997;11(4):306113

36. Young A, Dixey J, Cox N, et al. How does functional disability in early rheumatoid arthritis (RA) affect patients and their lives? Results of 5 years of follow-up in 732 patients from the Early RA Study (ERAS). Rheumatology. 2000;39(6):603-611. 
37. Feys HM, Weerdt WJ, Selz BE, et al. Effect of a therapeutic intervention for the hemiplegic upper limb in the acute phase after stroke. A singleblind, randomized, controlled multicenter trial. Stroke. 1998;29(4):785792.
38. Corrigan JD, Smith KK, Granger CV. Validity of the functional independence measure for persons with traumatic brain injury. Arch Phys Med Rehabil. 1997;78(8):828-834. 